\title{
Effects of Yoga on Dysmenorrhea: A Systematic Review of Randomized Controlled Trials
}

\author{
Hyun-Nam Ko ${ }^{1}$, Sam-Sun Le ${ }^{2}$ and Sang-Dol Kim ${ }^{3 *}$ \\ ${ }^{1}$ Department of Nursing, Jinju Health College, Jinju, Republic of Korea \\ ${ }^{2}$ Department of Nursing, Koje College, Koje, Republic of Korea \\ ${ }^{3}$ Department of Nursing, College of Health Science, Kangwon National University, Samcheok-si, Republic of Korea
}

"Corresponding author: Sang-Dol Kim, Department of Nursing, College of Health Science, Kangwon National University: 346 Hwangjo-gil, Dogye-eup, Samcheok-si, Gangwon-do 245-907, Republic of Korea, Tel: 82-33-540-3362; Fax: 82-033-540-3217; E-mail: nu11110@kangwon.ac.kr

Received date: October 10, 2016; Accepted date: December 01, 2016; Published date: December 05, 2016

Copyright: (c) 2016 Hyun-Nam K, et al. This is an open-access article distributed under the terms of the Creative Commons Attribution License, which permits unrestricted use, distribution, and reproduction in any medium, provided the original author and source are credited.

\author{
Abstract \\ Objectives: To assess the evidence for the effectiveness of yoga in the management of menstrual pain and the \\ symptoms associated with dysmenorrhea.
}

Methods: A search was conducted using CINAHL, the Cochrane library, Embase, PsyclNFO, PubMed, and KoreaMed electronic databases to identify randomized controlled trials (RCTs) reported effects of yogic intervention on dysmenorrhea published in any language between January 1966 and October 2014. Quality assessment was conducted using the Cochrane risk of bias tool.

Results: Two potential trials were identified of which two were included in the review. Quality critical appraisal had low or moderate risk of bias. The available data could only be included as a narrative description. A significant difference was observed between experimental and control groups in pain intensity and pain duration $(p<0.05)$ and thyroid-stimulating hormone $(p<0.002)$, follicle-stimulating hormone $(p<0.02)$, luteinizing hormone $(p<0.001)$, and prolactin $(p<0.02)$ were decreased significantly in the experimental group, compared with the control group.

Conclusions: There is evidence from two RCTs that yoga interventions may be favorable effective for dysmenorrhea. However the findings should be interpreted with caution due to the number of small RCTs and quality limitation partly. Therefore further high quality RCTs are required to investigate the hypothesis that yoga alleviates menstrual pain and the symptoms associated with dysmenorrhea, to confirm and further comprehend the effects of standardized yoga programs in dysmenorrhea.

Keywords: Dysmenorrhea; Yoga; Systematic review

Abbreviations: CONSORT: Consolidated Standards of Reporting Trials; IUCD: Intra-Uterine Contraceptive Device; OCP: Oral Contraceptive Pills; RCTs: Randomized Controlled Trials; VAS: Visual Analogue Scale

\section{Introduction}

Although the prevalence of dysmenorrhea varied in range from $25 \%$ of menstruating women to $90 \%$ of adolescent females or $45 \%$ to $95 \%$ of any age, dysmenorrhea seems to be the most common gynecological condition in women, regardless of age, race, or nationality [1-4]. Furthermore, dysmenorrhea is a critical global health issue in reproductive age women, as it causes school absences, poor academic performance, lost work time, and has a significantly negative affect on daily activities $[5,6]$. Dysmenorrhea is generally defined as difficult monthly flow and describes painful menstruation of uterine origin $[2,7]$.

Dysmenorrhea can be classified into two subtypes. The pathogenesis of primary dysmenorrhea is commonly explained by "an abnormal increase in vasoactive prostaglandins originating in secretory endometrium and menstrual fluid, which may induce myometrial hyperactivity and uterine tissue ischemia and pain" $[8,9]$.

In addition, various psychological problems have also been proposed $[8,9]$. Secondary dysmenorrhea can occur many years after menarche and is associated with identifiable pelvic pathology such as endometriosis $[8,9]$.

Dysmenorrhea is characterized by cramping lower abdominal pain that may radiate to the lower back and upper thighs and is commonly associated with nausea, headache, fatigue, diarrhea, lethargy, breast tenderness and emotional symptoms $[5-7,10]$.

Dysmenorrhea is usually treated with drugs such as oral contraceptive pills or non-steroid anti- inflammatory drugs [2,10]. A variety of alternatives for dysmenorrhea, such as transcutaneous electrical nerve stimulation, acupuncture, acupressure, topical heat, behavioral interventions, relaxation, and herbal and dietary therapies, are increasingly growing in attention $[2,8,11,12]$.

A growing body of evidence supports the belief that yoga benefits physical and mental health via down-regulation of the hypothalamicpituitary-adrenal axis and the sympathetic nervous system $[13,14]$. Yoga may be a safe and cost-effective intervention for managing menstrual problems [9]. Yoga plays an important role in reducing 
stress and sympathetic activity, increasing parasympathetic activity, improving one's quality of life, and decreasing psychological symptoms levels [3-19].

As stated, there is evidence for the benefit of yoga in reducing pain and symptoms of dysmenorrhea. However, the quality of the evidence deeds to be examined to establish whether or not we can advocate yoga as an alternative and complementary therapy for women with painful periods. Therefore, the aim of this review is to assess the evidence for the effectiveness of yoga in the management of menstrual pain and the symptoms associated with dysmenorrhea.

\section{Methods}

\section{Search strategy}

The review was planned and conducted in accordance with Consolidated Standards of Reporting Trials (CONSORT) guidelines for Reporting Parallel Group Randomized Trials [20]. We searched CINAHL, Cochrane Library, Embase, PsycINFO, PubMed, and KoreaMed electronic databases to identify RCTs published through October 2014. Our search terms were as follows: (1) yoga ("yoga" or "yoga nidra") and (2) dysmenorrhea ("dysmenorrhea" or "menstrual cramps" or "menstrual pain").

We manually searched the reference lists by 'footnote chasing' to identify any additional studies relevant to our analysis. Two independent investigators reviewed all the articles from the previous search based on the following selection criteria. Statistical practitioners trained these researchers in systematic review methods and metaanalytic operations. All potentially eligible studies were retrieved and the full-text articles were reviewed to determine whether they met the inclusion criteria.

To be eligible, studies had to meet the following conditions. The inclusion criteria was evaluated by two researchers independently using the criteria recommended by the Cochrane Menstrual Disorders and Subfertility Group and the Consolidated Standards of Reporting Trials $[7,12,20]$ :

Population: Women in the trials had to meet all the following inclusion criteria for the trial to be included in the review: dysmenorrhea (pain affecting daily activity or with a high baseline score); dysmenorrhea in the majority $(>50 \%)$ of menstrual cycles; dysmenorrhea for at least one day of menses; of reproductive age; primary or secondary dysmenorrhea. If participants in the trial met any of the exclusion criteria, the trial was not included in the review: With irregular or infrequent menstrual cycles (usually outside of the typical range of a 21 to 35 day cycle); using an intra-uterine contraceptive device (IUCD) or taking oral contraceptive pills (OCP).

Intervention: Randomized controlled trials were included that used yoga as an intervention to review or reduce symptoms associated with dysmenorrhea compared with no yoga.

Comparison: Any randomized controlled trials (RCTs) comparing yoga (as treatment) for dysmenorrhea versus no yoga;

Outcomes: Primary outcomes were; (1) pain relief (measured either by a visual analogue scale (VAS), other scale (menstrual disorders questionnaire), or dichotomous outcome (i.e. pain relief yes or no), (2) overall improvement in symptoms (measured by changes in dysmenorrhea symptoms, either self-reported or investigator-observed treatment effectiveness, or other similar measures), (3) pathophysiological parameters improvement (measured by change in hormone levels, serum homocysteine and nitric oxide levels etc.), (4) adverse effects from treatment (incidence and type of side effects).

Secondary outcomes were; (1) restriction of daily life activities (measured as the proportion of women who reported activity), (2) absence from work or school (measured as the proportion of women reporting absences from work or school, and also as hours or days of absence as a more selective measure), (3) requirement for medication additional to assigned treatment (measured as a proportion of requiring analgesics additional to their assigned treatment).

\section{Quality assessment}

Two reviewers independently conducted assessments using a critical appraisal Cochrane risk of bias tool RCTs, which was recommended by the Cochrane Handbook for systematic Reviews of Interventions [21]. The Cochrane risk of bias tool is a six-item list designed to assess sequence generation, allocation concealment, blinding, incomplete outcome data, selective outcome reporting, and other potential sources of bias. Each item was rated as "yes," "no," or "unclear".

According to the Cochrane Handbook, quality of clinical trials can divided into three levels. If the study design fully met the preceding six criteria, it is considered A level, which means the low risk of bias. B level would be assigned when one or more criteria were partly met.

If one or more criteria were not met, the study would be defined as $\mathrm{C}$ level, implying high risk of bias. Studies rated as $C$ level would be eliminated. Any disagreements were resolved by reviewers' discussion.

\section{Data synthesis}

No meta-analysis was performed as only two studies were identified due to heterogeneity among the included studies. Data are presented descriptively as no usable data were available.

\section{Results}

\section{Study description}

A total of 1,120 titles related to our search terms were screened. Among these, there were 1,025 potential trials identified from CHINAL, 5 from the Cochrane Library, 61 from KoreaMed, 6 from PsycINFO and 23 from the PubMed databases.

After the titles were retrieved a total of 257 studies were excluded either because they were duplicates or they were newsletters, commentaries or no target concepts which mean no dysmenorrhea.

The remaining 863 abstracts were retrieved. After assessing the abstracts, 858 studies were excluded because there was no yoga intervention. Five potential trials were identified in the search conducted in October 2014.

Five potentially relevant papers were retrieved for evaluation of full text. After the five full text assessment, three studies were excluded because two of them did not meet the selection criteria and one had no randomized trial. Figure 1 depicts the literature retrieval process. Characteristics of the included studies are presented in Table 1. 


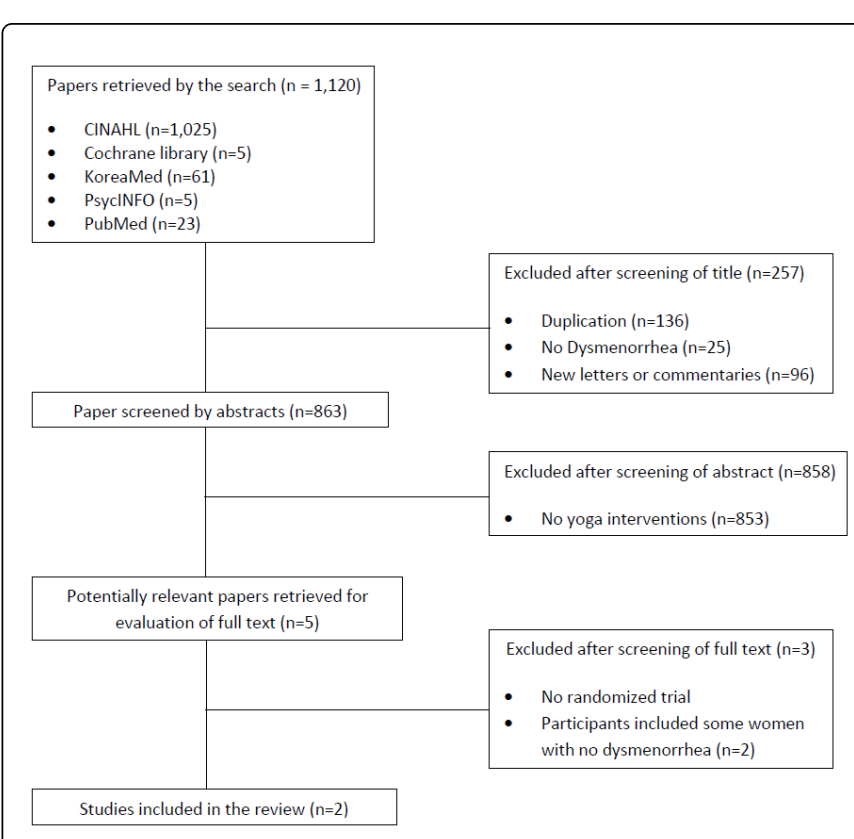

Figure 1: Flowchart of included studies through the literature searches.

\section{Participants and settings}

One RCTs originated in India and another from Iran. Studies were conducted at a medical university or university midwifery department. Participants were recruited from obstetrics and gynecological departments or by interviews at a university. Sample sizes in the 2 studies ranged from 92 to 126 participants and totaled 218 participants. Participants' mean age ranged from 18.0 years to 28.5 years with a median of 23.2 years. Participants had a primary dysmenorrhea in 1 RCT and menstrual abnormalities such as pathological amenorrhea, dysmenorrhea, oligomenorrhea, polymenorrhea, menorrhagia, metrorrhagia, and hypomenorrhea in 1 RCT.

\section{Design and intervention}

Two RCTs were identified in this review. Yoga traditions were heterogeneous between studies: 1 RCT used three poses and 1 RCT used yoga nidra. One yoga program included yoga postures such as cobra, cat and fish while the other program included resolve, rotation of consciousness, awareness of the breath, feeling and sensation, visualization, and ending the practice with resolve. Program length, frequency, and duration of one trial was one $20 \mathrm{~min}$ session a day for 14 days, another trial was $35 \mathrm{~min}$ to $40 \mathrm{~min}$ session a day, 5 days per week for 6 months. Yoga was performed under the guidance and supervision of yoga experts and faculty members in one trial, while another trial used a booklet with level to level explanations along with movements and breathing. One RCT compared yoga to no treatment and another RCT compared yoga nidra with conventional medication to conventional medication only.

\section{Outcomes}

Two studies were identified that compared a control group with a yoga intervention group and evaluated the effect on dysmenorrhea.
The available data could only be included as a narrative description. A significant difference was observed between experimental and control groups in pain intensity and pain duration $(\mathrm{p}<0.05)$. Thyroidstimulating hormone $(\mathrm{p}<0.002)$, follicle-stimulating hormone $(\mathrm{p}<0.02)$, luteinizing hormone $(\mathrm{p}<0.001)$, and prolactin $(\mathrm{p}<0.02)$ were decreased significantly in the intervention group, compared with the control group. Neither included trial reported data on overall improvement in symptoms, adverse effects of treatment, restriction of daily activities, or absence from work or school etc.

\section{Critical appraisal of quality}

Assessments on each methodological quality item for all included trials are described in Table 1. Of two trials, one trial was quality level $\mathrm{A}$, another trial was quality level $\mathrm{B}$.

\section{Discussion}

The purpose of this review was to assess the evidence for the effectiveness of any yoga interventions for the primary or secondary dysmenorrhea when compared to no yoga. A meta-analysis combining results from all the trials were not feasible due to only two identified studies and heterogeneity among them. Data were reported descriptively as no usable data were available.

Only two RCTs were identified and included in this review. Interventions included yoga pose and yoga nidra to manage menstrual pain and symptoms $[3,4]$. Of the two, one trial reported a significant decrease in pain intensity and pain duration during the menstrual phase of the trained group. The other trial reported a significant decrease in hormone levels such as thyroid-stimulating hormone, follicle-stimulating hormone, luteinizing hormone, and prolactin in the intervention group compared to the control group. This study also stated that after yoga nidra practice, menstrual symptoms such as painful cramps, heavy bleeding, and irregular periods were relieved in participants. Wonderfully, the symptoms were also reduced in both groups. The mechanism behind yoga effectiveness for dysmenorrhea is still unclear. However, in spite of both groups having received medication, reductions of the symptoms in the yoga group were higher than in the control group. Therefore, these results support yoga practice as a positive manager of menstrual pain and dysmenorrhea symptoms.

According to the mechanism which an abnormal increase in vasoactive prostanoids in the endometrium and menstrual fluid may induce myometrial hyperactivity and tissue ischemia subsequently $[2,4,8,22,23]$, a yoga intervention improves blood flow at the pelvic level as well as stimulating the release of $B$ endorphine acting as nonspecific analgesics [4]. In addition, another study reported that yoga poses improve spinal flexibility and strengthens muscles in the back and yoga nidra means psychic sleep which may induce deep relaxation and, subsequently decrease oxygen consumption causing pain relief $[11,18,22,24]$.

Besides, these results support research findings demonstrating that relaxation training is an effective treatment for spasmodic dysmenorrhea or producing improvements in general measures of dysmenorrhea [25]. As stated, these reviewers identified the two RCTs in this review as having evidence for the favorable effectiveness of yoga on dysmenorrhea management. 
Citation: Hyun-Nam K, Sam-Sun L, Sang-Dol K (2016) Effects of Yoga on Dysmenorrhea: A Systematic Review of Randomized Controlled Trials. Altern Integr Med 5: 226. doi:10.4172/2327-5162.1000226

Page 4 of 5

\begin{tabular}{|c|c|c|c|c|c|c|c|}
\hline \multirow{3}{*}{$\begin{array}{l}\text { Study, year, } \\
\text { location }\end{array}$} & \multirow[t]{2}{*}{ Participants } & \multicolumn{2}{|l|}{ Interventions } & \multirow[t]{2}{*}{ Outcome measures } & \multirow[t]{2}{*}{ Main results } & \multirow{2}{*}{$\begin{array}{l}\text { Adverse } \\
\text { events }\end{array}$} & \multirow[t]{2}{*}{ Limitations } \\
\hline & & Experimental group & Control group & & & & \\
\hline & $\begin{array}{l}\text { Population } \\
\text { Sample size } \\
\text { (N;EG, CG) } \\
\text { Mean age (age } \\
\text { range) } \\
\text { Drop out } n(\%)\end{array}$ & \multicolumn{2}{|l|}{$\begin{array}{l}\text { Interventions } \\
\text { Delivery method } \\
\text { Duration } \\
\text { Interventionist }\end{array}$} & & & & \\
\hline $\begin{array}{l}\text { Rani et al. [9], } \\
\text { India/Uttar } \\
\text { Pradesh }\end{array}$ & $\begin{array}{l}\text { University students } \\
\text { with menstrual } \\
\text { disorders } \\
\mathrm{N}=126 \quad(\mathrm{EG}: \quad 65, \\
\mathrm{CG}: 61) \\
28 \text { years (-) } \\
24(31.9)\end{array}$ & $\begin{array}{l}\text { Yoga nidra+Conventional } \\
\text { medication } \\
35 \text { min to } 40 \text { min per day, } \\
5 \text { days per week in the } \\
\text { morning } \\
6 \text { months } \\
\text { Yoga experts and faculty } \\
\text { members }\end{array}$ & $\begin{array}{l}\text { only } \\
\text { Conventional } \\
\text { medication }\end{array}$ & $\begin{array}{l}\text { Pathophysiological } \\
\text { parameters } \\
\text { TSH } \\
\text { FSH } \\
\text { LH } \\
\text { Prolactin } \\
\text { Progesterone } \\
\text { Estradiol } \\
\text { Testosterone } \\
\text { DHEA-S }\end{array}$ & 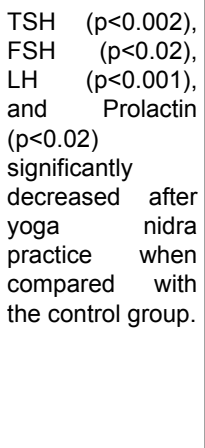 & None & $\begin{array}{l}\text { All menstrual } \\
\text { disorders were } \\
\text { included. } \\
\text { The sample size was } \\
\text { not large enough to } \\
\text { analysis hypo and } \\
\text { hypermenorrhic } \\
\text { subgroup separately. } \\
\text { The phase of the } \\
\text { menstrual cycle was } \\
\text { based on the } \\
\text { participant's reports } \\
\text { not on ultrasound } \\
\text { scans. }\end{array}$ \\
\hline $\begin{array}{l}\text { Rakhshaee } \\
\text { [11], } \\
\text { Iran/Rasht }\end{array}$ & $\begin{array}{l}\text { University students } \\
\text { with primary } \\
\text { dysmenorrhea } \\
\mathrm{N}=92 \text { (EG: } 50, \mathrm{CG} \text { : } \\
42) \\
20 \text { years (18-22) } \\
28(30.4)\end{array}$ & $\begin{array}{l}\text { Yoga movement with } \\
\text { cobra, Cat, and } \\
\text { fish poses } \\
120 \text { min per day, } \\
14 \text { days for menstrual } \\
\text { cycle } \\
\text { Booklet described the } \\
\text { yoga }\end{array}$ & $\begin{array}{l}\text { Did not receive } \\
\text { any intervention }\end{array}$ & $\begin{array}{l}\text { Pain relief } \\
\text { pain intensity } \\
\text { Pain duration }\end{array}$ & $\begin{array}{l}\text { A significant } \\
\text { difference was } \\
\text { observed } \\
\text { between } \\
\text { experimental and } \\
\text { control groups in } \\
\text { pain intensity and } \\
\text { pain duration } \\
(p<0.05) \text {. }\end{array}$ & None & $\begin{array}{l}\text { The obtained data is } \\
\text { based on female } \\
\text { adolescent } \\
\text { participants' } \\
\text { responses. }\end{array}$ \\
\hline
\end{tabular}

Table 1: Characteristics of included randomized controlled trials.

\begin{tabular}{|l|l|l|l|l|l|l|}
\hline Study, year & $\begin{array}{l}\text { Random } \\
\text { allocation }\end{array}$ & $\begin{array}{l}\text { Allocation } \\
\text { concealment }\end{array}$ & Blinding & $\begin{array}{l}\text { Incomplete } \\
\text { outcome }\end{array}$ & $\begin{array}{l}\text { Selective } \\
\text { reporting }\end{array}$ & Yes \\
\hline Rani et al. [9] & Yes & Yes & Yes & Yes & Yes & Yes \\
\hline Rakhshaee [11] & Yes & Unclear & No & Yes & Bes \\
\hline
\end{tabular}

Yes: criteria met; No: criteria not met; Unclear, unclear whether criteria were met

Table 2: Methodological quality summary of all included studies.

In the two trials included in this review, they were too heterogeneous in the participants' condition (primary dysmenorrhea or all menstrual disorders), the type of yoga (three yoga poses composed of physical exercise and breathing or yoga nidra combining meditation and relaxation), interventionist (only booklet or yoga experts), duration of the intervention delivery (14 days for menstrual cycle or 6 months), outcome measures (pain intensity and pain duration or hormonal responses) etc. The rate of drop out was also high in the two RCTs. In one trial, 24 (31.9\%) women were lost to the analysis for several reasons such as acute pain, family problems, transportation problems, scheduling, or being non-responsive, etc. In another trial, 28 (30.4\%) participants did not complete the study because they had an irregular menstrual cycle and failed to comply.

Overall, the trials in this review had no adverse effects, stated that yoga poses are a safe and simple treatment for primary dysmenorrhea.
The quality rating of the trials included in this review had a low or moderate risk of bias. One trial was unclear about how treatment allocation was concealed. One of the two trials was single blind and the other did not mention blinding. The trials in this review had moderate or high methodological quality (Table 2). However, no strong conclusion can be made due to the number of small trials and other methodological considerations.

This strength of this systematic review includes the use of strict methodological criteria. Major strengths of this group of studies include study, the use of randomization, and the quality of measurement tools. Both studies were RCTs. This may be the first comprehensive review of yoga for dysmenorrhea.

Limitations were also identified. Menstrual disorders such as menorrhea, dysmenorrhea, oligomenorrhea, polymenorrhea, 
menorrhagia, metrorrhea, and hypomenorrhea were included in one trial all together. The sample size was also not large enough to analyze the hypomenorrhic group and hypermenorrhic subgroups separately. The methods of the participants' selection have the following flaws. The phase of the menstrual cycle was based on the participant's reports not on ultrasound scans. The obtained data is also based on female adolescent participants' responses. Generalizability of findings from these two studies is limited due to the number of small trials and limited quality partly. However, they provide a strong basis for future studies and suggest that yoga could provide a safe, cost-effective therapy for the growing public health issue of dysmenorrhea. There is currently a lack of available evidence to support the use of yoga in the alleviation of symptoms associated with dysmenorrhea. The broader health benefits of yoga should be discussed with women experiencing dysmenorrhea. Future research should consider these limitations. Furthermore, this review contributes to the development of knowledge in complementary and alternative medicine about how female adolescents with dysmenorrhea can manage themselves.

In conclusion, although this review has a limited number of small trials and homogeneity among them, and limited quality partly, findings from the two trials suggest that yoga practice can effectively alleviate menstrual pain and the symptoms associated with dysmenorrhea. However further high-quality RCTs are needed to confirm and further comprehend the effects of standardized yoga programs to control menstrual pain and symptoms in dysmenorrhea.

\section{Acknowledgement}

This study was supported by 2016 Research Grant from Kangwon National University (No. 620160142).

\section{References}

1. Osayande A, Mehulic S (2014) Diagnosis and initial management of dysmenorrhea. Am Fam Physician 89: 341-346.

2. Perry M (2012) Treatment options for dysmenorrhea. Nurs Pract 23: 195-198.

3. Shah M, Monga A, Patel S, Shah M, Bakshi H (2013) A study of prevalence of primary dysmenorrhea in young students-a cross sectional study. Healthline 4: 30-34.

4. Proctor ML, Farquhar CM (2006) Diagnosis and management of dysmenorrhoea. BMJ 332: 1134-1138.

5. Seven M, Güvenç G, Akyüz A, Eski F (2014) Evaluating dysmenorrhea in a sample of Turkish nursing students. Pain Manage Nurs 15: 664-671.

6. Cheng HF (2011) Management of perimenstrual symptoms among young Taiwanese nursing students. J Clin Nurs 20: 1060-1067.

7. Brown J, Brown S (2010) Exercise for dysmenorrhea. Cochrane Database Syst Rev CD004142.
8. Chien LW, Chang HC, Liu CF (2013) Effect of yoga on serum homocysteine and nitric oxide levels in adolescent women with and without dysmenorrhea. J Altern Complement Med 19: 20-23.

9. Rani M, Singh U, Agrawal GG, Natu SM, Kala S, et al. (2013) Impact of Yoga nidra on menstrual abnormalities in females of reproductive age. J Altern Complement Med 19: 925-929.

10. Han SH, Hur MH, Buckle J, Choi JY, Lee MS (2006) Effect of aromatherapy on symptoms of dysmenorrhea in college student: a randomized placebo-controlled clinical trial. J Altern Complement Med 12: 535-541.

11. Rakhshaee Z (2011) Effect of three yoga poses (cobra, cat and fish poses) in women with primary dysmenorrhea: a randomized clinical trial. J Pediatr Adolesc Gynecol 24: 192-196.

12. Proctor ML, Murphy PA, Pattison HM, Suckling JA, Farquhar C (2007) Behavioural intervention for dysmenorrhea. Cochrane Database Syst Rev CD002248.

13. Kanojia S, Sharma VK, Gandhi A, Kapoor R, Kukreja A, et al. (2013) Effect of yoga on autonomic functions and psychological status during both phases of menstrual cycle in young healthy females. J Clin Diagn Res 7: 2133-2139.

14. Beets MW, Mitchell E (2010) Effects of yoga on stress, depression, and health-related quality of life in a nonclinical, bi-ethnic sample of adolescents: a pilot study. Hisp Health Care Int 8: 47-53.

15. Tul Y, Unruh A, Dick BD (2011) Yoga for chronic pain management: a qualitative exploration. Scand J Caring Sci 25: 435-443.

16. Kuntsevich V, Bushell WC, Theise ND (2010) Mechanism of yogic practices in health, aging, and disease. Mt Sinai J Med 77: 559-569.

17. Ross A, Thomas S (2010) The health benefits of yoga and exercise: a review of comparison studies. J Altern Complement Med 16: 3-12.

18. Satyanada SS (2006) Yoga nidra. Yoga Publication Trust, Munger, Bihar, India.

19. Daley AJ (2008) Exercise and primary dysmenorrhea. A comprehensive and critical review of the literature. Sports Med 38: 659-670.

20. Schulz KF, Altman DG, Moher D (2010) CONSORT 2010 statement: updated guidelines for reporting parallel group randomized trials. J Clin Epidemiol 63: 834-840.

21. Higgins JPT, Green S (2011) Cochrane Handbook for Systematic Reviews of Interventions. The Cochrane Collaboration, John Wiley and Sons, New Jersey, USA.

22. Nayak NN, Shankar K (2004) Yoga: A therapeutic approach. Phys Med Rehabil Clin N Am 15: 783-798.

23. French L (2005) Dysmenorrhea. Am Fam Physician 71: 285-291.

24. Sharma M (2014) Yoga as an alternative and complementary approach for stress management: a systematic review. J Evid Based Complementary Altern Med 19: 59-67.

25. Sigmon ST, Nelson RO (1988) The effectiveness of activity scheduling and relaxation training in the treatment of spasmodic dysmenorrhea. J Behav Med 11: 483-495. 